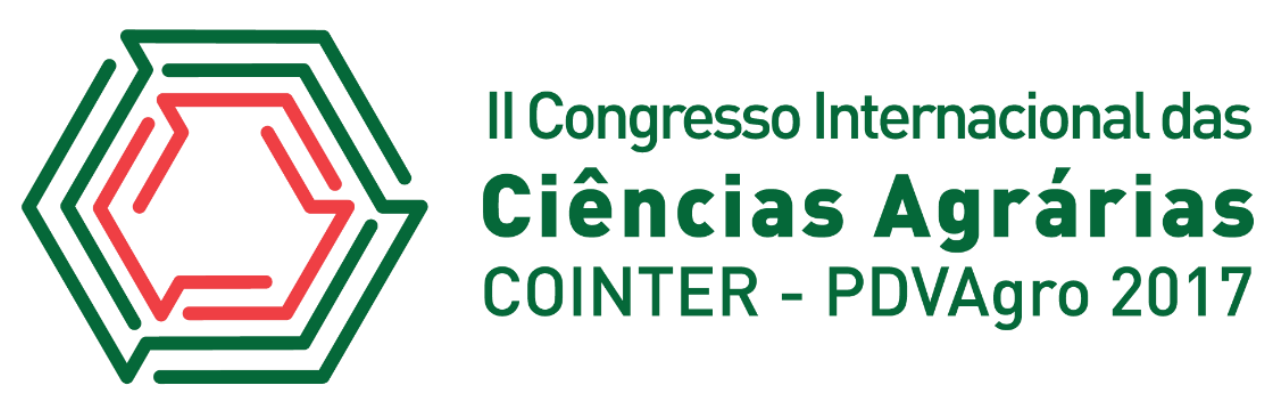

\title{
PERFIL SOCIOECONÔMICO DOS FEIRANTES DA FEIRA LIVRE DA QUATORZE DE MARÇO, CAPANEMA, PARÁ, BRASIL
}

\section{${ }^{1}$ SILVA, Jaciara Firmino da ${ }^{1}$; MUNIZ, Carla Caroline Santana ${ }^{2}$; COSTA, Eduardo Kenneth de Oliveira da ${ }^{3}$; JÚNIOR, Antônio Barbosa Smith ${ }^{4}$; MELO JÚNIOR. Luiz Introdução Cláudio Moreira ${ }^{5}$}

De acordo com Vieira (2004), as feiras livres são uma prática comercial muito antiga, que há muito tempo fomentam o suprimento de diversos gêneros alimentícios de muitas cidades no Brasil. Embora percebida como modelo comercial ultrapassado, que preserva características medievais, Coutinho et al. (2006) visualizam as feiras como provedores do desenvolvimento econômico e social, fomentando a economia das pequenas cidades interioranas.

A atividade da agricultura familiar, que já foi denominada trabalho de subsistência, é considerada, atualmente, como importante abastecedora do mercado interno e do mercado externo. Essa atividade apresenta números relevantes de produção no âmbito nacional, com destaque para produtos como o leite, as carnes (suínos e aves), os ovos, a cebola, o fumo, o milho, o feijão, a mandioca, a soja, o arroz, a banana, a laranja, o café e a uva (GUILHOTO et al., 2007).

A constante procura por alimentos frescos, supostamente cultivados sem o uso ou com o uso mais ponderado de defensivos agrícolas, e os preços mais acessíveis são atrativos que condicionam diferentes tipos de consumidores a preferirem as feiras livres aos mercados tradicionais (ROCHA et al., 2009). Neste sentido, Costa et al. (2007) afirmam que, por sua maior diversidade e disponibilidade de produtos frescos, as feiras se tornam mais atrativas em relação aos supermercados e frutarias. Outros fatores que estimulam essa preferência são a dinâmica peculiar de negociação do preço e do atendimento personalizado, possibilitando uma relação bastante próxima com o produtor feirante. Possivelmente, estejam aí os principais motivos que permitem explicar a persistência das feiras em relação às modernas redes de varejo.

\footnotetext{
1 1Agronomia, universidade Federal Rural da Amazônia, jacyarafirminno@gmail.com 2Agronomia, universidade Federal Rural da Amazônia, carolinesantana23@yahoo.com.br 3Agronomia universidade Federal Rural da Amazônia,kennethcosta63@gmail.com 4Agronomia, universidade Federal Rural da Amazônia,juniorsmith147@ hotmail.com 5Professor Doutor, universidade Federal Rural da Amazônia, luiz.mmelo@hotmail.com
} 
Este trabalho teve por objetivo traçar o perfil socioeconômico dos feirantes que comercializam produtos na feira livre da Quatorze de Março na cidade de Capanema, Nordeste Paraense.

\section{Fundamentação Teórica}

No Brasil, a origem das feiras livres se confunde com a história nacional. Elas se multiplicaram no processo Brasil-Colônia, desempenhando papéis importantes, não só nos primeiros povoamentos, mas também na estrutura da organização econômica e social das populações. As feiras se expandiram desempenhando um importante papel no abastecimento urbano dos mais diversos produtos agropecuários (SACCO DOS ANJOS, et al. 2005).

Segundo Ricotto (2004), as feiras livres exercem um importante papel na estabilização econômica e social, principalmente da agricultura familiar, sendo capaz de gerar mudanças e reconversão de pequenos e médios agricultores. Neste contexto, as feiras livres vêm se tornando fatores essenciais para a manutenção do desenvolvimento rural, comercial e econômico da agricultura e de outros meios produtivos.

\section{Metodologia}

A feira da Quatorze de Março é uma das mais conhecidas do município de CapanemaPA. Ela funciona todos os dias da semana e cumpre importante papel na economia do município. A pesquisa foi realizada no dia 08 de abril de 2017, sendo aplicadas 10 (dez) entrevistas semiestruturadas entre os feirantes fixos da referida feira. $\mathrm{O}$ roteiro das entrevistas continha questões relativas ao perfil socioeconômico dos feirantes, à origem dos produtos comercializados e às preocupações com o uso de agrotóxicos e formas alternativas ou ideias para o melhor desenvolvimento do trabalho da feira.

Os dados obtidos foram sistematizados no Microsoft Office Excel 2013 para posteriores análises qualitativas e quantitativas.

\section{Resultados e Discussões}

A maioria dos entrevistados (60\%) são do sexo feminino e $40 \%$ do sexo masculino. Esse dado nos remete à importância das mulheres na comercialização de produtos hortifrutigranjeiros na cidade de Capanema-PA, dado similar encontrado por Gomes (2013), ao analisar feiras livre do interior baiano, nas quais a participação feminina no mundo do 
trabalho informal é assídua, destacando-se a comercialização de produtos populares em feiras livres em centros urbanos.

As feiras livres, geralmente, são alternativas de trabalho para pessoas com baixa escolaridade. Cerca de $80 \%$ dos entrevistados não têm o ensino fundamental completo e apenas 20\% têm ensino médio completo. Este dado também foi encontrado por Rocha (2009), que estudou os feirantes da Feira do Produtor de Passo Fundo-RS e constatou que o grau de escolaridade mais comum entre os feirantes é o ensino fundamental.

Quando perguntados sobre a forma como são produzidos os alimentos comercializados, $40 \%$ dos entrevistados (Figura 1) não souberam responder acerca da procedência dos seus produtos. Esse dado é relevante quando se analisa a origem do que é comercializado nas feiras livres, nas quais é esperado um produto livre de agrotóxicos e de boa qualidade. No Brasil, estima-se que dois terços da população está exposta, em diferentes níveis, aos efeitos nocivos dos agrotóxicos utilizados nas plantações e criações de animais, em função do consumo de alimentos contaminados (PERES, et al. 2005).

Figura 1: Gráfico mostrando o grau de conhecimento dos entrevistados sobre de que forma os produtos são produzidos e a preocupação destes com o uso de agrotóxicos.

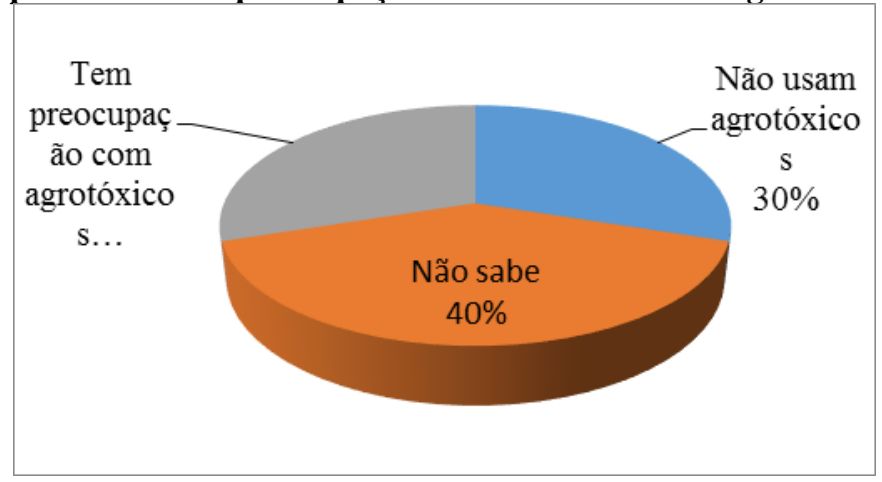

Fonte: Dados de campo (2017)

No que diz respeito à venda dos produtos, foi possível verificar que $70 \%$ dos feirantes destinam as sobras da venda ao lixo. Este resultado aponta a necessidade de trabalhos envolvendo a educação ambiental nas feiras sobre as alternativas de uso das sobras e o aproveitamento dos resíduos, podendo ser destinados para outras finalidades, como a realização de adubos orgânicos. Esses dados corroboram com estudos realizados por Barbosa et al. (2014), que também constatou que 95\% dos feirantes da área estudada não têm conhecimento sobre os danos causados pela decomposição dos alimentos desperdiçados no local de estudo.

Quando perguntados sobre os produtos hortifrutigranjeiros que são comercializados, $28 \%$ afirmaram ser produzidos em Capanema (Figura 3). Isto reflete nos preços dos produtos, 
que adquirem valores de transporte mais baratos e, por sua vez, os alimentos chegam à mesa do cliente com valores mais acessíveis. Porém, $27 \%$ dos feirantes não sabem onde os produtos são produzidos, pois suas compras vêm de terceiros. Castanhal, Bragança e Belém são as cidades nas quais os feirantes mais compram mercadorias, pelo fato da maior produção e do fácil transporte, tornando mais lucrativa a atividade.

Figura 3: Gráfico demostrando onde são produzidos os produtos vendidos pelos feirantes.

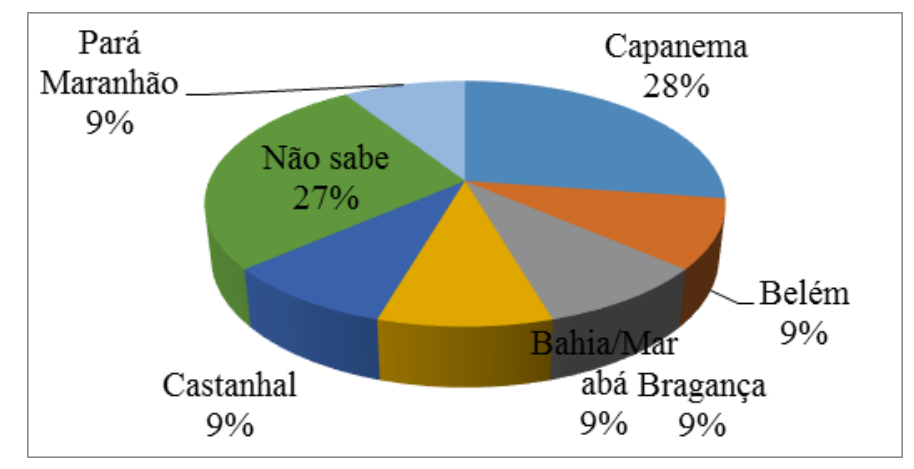

Fonte: Dados de Campo (2017)

Quanto às instalações, 50\% dos entrevistados afirmaram que a feira não oferece um local adequado, pois gostariam de uma área maior com uma banca fixa, para melhor atender os seus clientes. Cerca de $10 \%$ gostariam de ter maior apoio da prefeitura para obter uma estrutura adequada de trabalho.

Os produtos mais comercializados (Figura 4) pelos feirantes, como alface, coentro, couve, pepino, chicória, pimentão e tomate, são de suma importância para a economia local. No entanto, são hortifrutigranjeiros encontrados nas proximidades do município, como visto anteriormente, por este fato são abundantes na região, o que leva a grande demanda dos mesmos.

Figura 4: Produtos hortifrutigranjeiros mais comercializados.

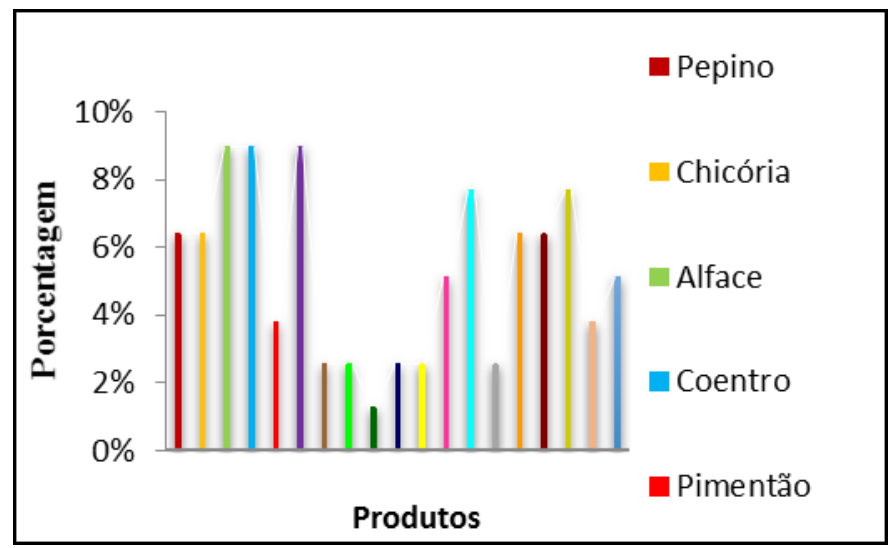

Fonte: Dados de Campo (2017) 


\section{Conclusão}

A feira livre representa, hoje, uma das mais importantes formas de comercialização de produtos provenientes da agricultura familiar. Os produtos ofertados na feira da Quatorze de Março não são produzidos pelos próprios feirantes, sendo adquiridos de terceiros, oriundos de cidades vizinha a Capanema-PA. Os feirantes enfatizaram a carência de estrutura no local e a falta de apoio do poder público, uma vez que o bom desenvolvimento da atividade necessita de apoio externo, para que assim haja o aumento da renda desses trabalhadores.

\section{Referências}

BARBOSA, A. E. S; SANTOS, F. de A. P. dos; IZIDORIO, O. M. Desperdício ou reaproveitamento de alimentos comercializados na Feira do produtor Rural do município de Boa Vista/RR. 2014.16f. (Curso de Tecnologia em Gestão Ambiental) - Faculdade Estácio da Amazônia. Boa Vista, 2014.

COUTINHO, E. P.; NÓBREGA, H. C. N.; NEVES H. C. N.; SILVA, E.M. G. S. Feiras Livres do Brajo Paraíbano: Crise e Perspectivas. XLIV CONGRESSO DA SOBER "Questões agrárias, educação no campo e desenvolvimento". Fortaleza, 2006.

COSTA, T.R. et al. $1^{\circ}$ Reunião de Dinamização da Feira do Produtor e Município de Paiçandu- REDIFEIRA. Universidade Estadual de Maringá, 2007.

GUILHOTO, J. J. M. et al. PIB da Agricultura Familiar: Brasil e Estados. Brasília. NEAD/MDA/FIFE, 2007.

GOMES, F. A; Silva, F. S. J; SANTOS, A. A; SANTANA, P. G. W; SANTOS, G. A. J. Perfil Socioeconômico, 2013.

RICOTTO. A.J. Uma rede de produção e comercialização alternativa para agricultura familiar: o caso das feiras livres de Misiones, Argentina. 152f. 2002. Dissertação de (Mestrado. Programa de Pós-Graduação em Desenvolvimento rural ). Universidade Federal do Rio Grande no sul. 2002.

ROCHA, H. C.; COSTA, C.; CASTOLDI, F. L.; CECCHETTI, D.; CALVETE, E. O.; LODI, B. S. Perfil socioeconômico dos feirantes e consumidores da Feira do Produtor de Passo Fundo, RS. Ciência Rural, Santa Maria, 2009

PERES, F; ROZEMBERG, B; LUCCA, S. Percepção de riscos no trabalho rural em uma região agrícola do Estado do Rio de Janeiro, Brasil: agrotóxicos, saúde e ambiente. Caderno de Saúde Pública, Rio de Janeiro, v. 21. p.1836-1844, nov-dez, 2005.

SACCO DOS ANJOS, F.; GODOY, W.I.; CALDAS, N. V. As feiras livres de pelotas sob império da globalização: perspectivas e tendências. Pelotas: Editora e Gráfica Universitária, 2005.

VIEIRA, R. Dinâmicas da feira livre do município de Taperoá. 2004. Monografia. (Trabalho de conclusão do Curso de Geografia) - Universidade Federal da Paraíba, João Pessoa, 2004. 